
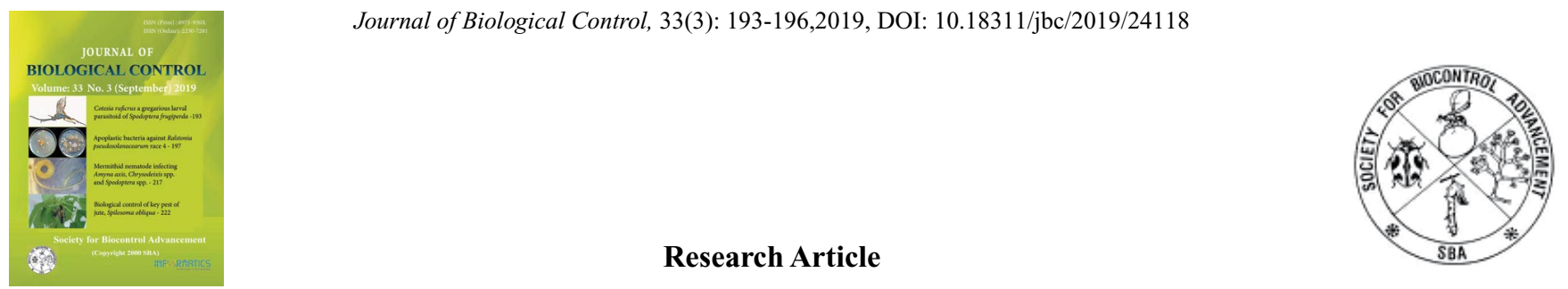

\title{
Cotesia ruficrus (Haliday, 1834) (Hymenoptera: Braconidae) emerging as a common natural parasitoid of Spodoptera frugiperda (J. E. Smith) (Lepidoptera: Noctuidae) in Indian maize fields
}

\author{
ANKITA GUPTA ${ }^{*}$, S. RAMESH BABU ${ }^{2}$ and M. SAMPATH KUMAR ${ }^{1}$ \\ ${ }^{1}$ ICAR-National Bureau of Agricultural Insect Resources, H. A. Farm Post, Bellary Road, Hebbal, Bengaluru - 560024, \\ Karnataka, India \\ ${ }^{2}$ Agricultural Research Station, MPUAT, Borwat Farm, Banswara - 327001, Rajasthan, India \\ ${ }^{*}$ Corresponding author E-mail: ankitagupta.nbaii@gmail.com
}

ABSTRACT: Field surveys conducted during 2018-2019 in the maize fields infested with Spodoptera frugiperda (J. E. Smith) (Lepidoptera: Noctuidae) in Karnataka, Tamil Nadu, Rajasthan and Meghalaya revealed that Cotesia ruficrus (Haliday) (Hymenoptera: Braconidae) was the common gregarious larval parasitoid in the maize fields parasitizing $S$. frugiperda. This is the first report of $C$. ruficrus parasitizing $S$. frugiperda in India, earlier reports being from Trinidad and Tobago. The present study (using integrated approach) provides morphological and molecular identification details along with host data, cocoon characters and geographical distribution of C. ruficrus.

KEYWORDS: Fall army worm, larval parasitoid

(Article chronicle: Received: 03-08-2019; Revised: 15-09-2019; Accepted: 20-09-2019)

\section{INTRODUCTION}

Cotesia ruficrus (Haliday, 1834) (Hymenoptera: Braconidae) also known from various synonyms Microgaster ruficrus Haliday, 1834, Apanteles antipoda (Ashmead, 1900), Apanteles anila (Ashmead, 1904), Apanteles sydneyensis (Cameron, 1911), and Apanteles narangae (Viereck, 1913) has a wide range of geographical distribution namely Afrotropical, Australasian, Neotropical, Oriental, and Palaearctic (Yu et al., 2016). Wilkinson (1928) mentioned many hosts of this parasitoid - Agrotis sp. as the host of $A$. antipoda; Naranga diffusa Walker as the host of $A$. narangae; some other hosts like Hypsipyla robusta Moore and Perigea capensis Guen. Wilkinson (1928) examined a series of $A$. antipoda wasps bred from the larvae of Spodoptera mauritia Boisd., which is interesting to note in the present context, as C. ruficrus was recorded from the same host genus. More specifically, C. ruficrus is also recorded parasitizing the pestiferous host $S$. frugiperda from Trinidad and Tobago (CABI, 2019). Gupta \& FernándezTriana (2014) reported C. ruficrus from Spodoptera sp. in
Karnataka and from an indeterminate larva feeding on maize in the Andamans and Nicobar Islands in 2012. The present study not only reports and confirms the identity of C. ruficrus (combining morphology, host data and Cytochrome Oxidase I - COI gene) additionally also highlights the affinity of natural parasitism by the native parasitoids towards the notorious invasive pest $S$. frugiperda in India which indeed is a good indication of its active and expanding parasitoid complex. A brief diagnosis of the wasp is also provided to aid researchers in quick identification.

\section{MATERIALS AND METHODS}

Larvae of Spodoptera frugiperda were collected from the maize fields (multiple locations) in southern India (Karnataka and Tamil Nadu) in 2018-19 and during February to April, 2019 in Banswara (north-western part of India) which is located in the humid southern plain zone of Rajasthan. The field collected larvae were reared in the laboratory at $25+2^{\circ} \mathrm{C}$ and $60-70 \%$ humidity on the maize leaves (provided ad libitum). Parasitoids were collected from the infested larvae 
of S. frugiperda and were preserved in $95 \%$ ethanol at $-20^{\circ} \mathrm{C}$ until further use.

Morphological studies were conducted at the ICAR- National Bureau of Agricultural Insect Resources, Bengaluru. The specimens reared from $S$. frugiperda were compared with the types and voucher specimens present in the Natural History Museum, London (BMNH) by the first author. DNA extraction, amplification and sequencing were done at Banswara by the second author for the specimens collected from Rajasthan. A portion of the tissue was dissected, air-dried for few minutes and rinsed with molecular grade water to remove the excess ethanol in the sample. Total genomic DNA was extracted using DNA Sure Tissue mini kit (Nucleo-pore, Genetix Brand, India), following the manufacturer's instructions. The intact genomic DNA was visualized in $1.2 \%$ agarose gel (Pure Gene, Genetix Biotech India PVT. Ltd., New Delhi). The concentration of DNA sample was adjusted to $50 \mathrm{ng} / \mu \mathrm{l}$ and stored at $-20^{\circ} \mathrm{C}$ for further use. The PCR reaction was carried out for the amplification of Cytochrome Oxidase subunit I (COI) gene which is of $\sim 700$ by using universal primers LCO1490 (5'-GGTCAACAAATCATAAAGATATTGG-3') and HCO2198 (5'-TAAACTTCAGGGTGACCAAAAAAT CA3') (Folmer et al., 1994). PCR (C1000Touch ${ }^{\text {TM }}$ Thermal cycler of Bio-Rad, $\mathrm{U}$ ) was performed with initial denaturation for $4 \mathrm{~min}$ at $94^{\circ} \mathrm{C}$, followed by 35 cycles of $30 \mathrm{sec}$ denaturation at $94^{\circ} \mathrm{C}, 45 \mathrm{sec}$ primer annealing at $47^{\circ} \mathrm{C}, 45 \mathrm{sec}$ initial extension at $72^{\circ} \mathrm{C}$ and a final extension of 20 min at $72^{\circ} \mathrm{C}$ (Rama Subramanian et al., 2016). The PCR amplification was performed for $50 \mu \mathrm{L}$ containing $25 \mu \mathrm{L}$ DreamTaq PCR Master Mix (2X) (Thermo Fisher, Scientific, UK), $2 \mu \mathrm{L}$ of template DNA, 10 pmol of each forward and reverse primer and final volume was made by using nuclease free water. The amplified PCR products were separated by electrophoresis in a $1.2 \%$ agarose gel containing ethidium bromide $(0.5 \mu \mathrm{g} / \mu \mathrm{L})$ for $60 \mathrm{~min}$ at $80 \mathrm{~V}$ (BIO-RAD, USA) and visualized in gel documentation system (Gel Doc ${ }^{\mathrm{TM}}$ EZ Imager, BIO-RAD, USA). The PCR products were purified by using GeneJET PCR purification Kit (Thermo Fisher, Scientific, UK) and sequenced by using ABI PRISM 3730xl Genetic Analyzer develop by Applied Biosystems, USA (Agile Life science Technologies India Pvt. Ltd, Pune).

\section{RESULTS AND DISCUSSION}

Detailed morphological and molecular characterization of the gregarious larval parasitoid Cotesia ruficrus was done.

\section{Cotesia ruficrus (Haliday, 1834)}

Microgaster ruficrus Haliday, 1834. Apanteles antipoda (Ashmead, 1900).
Apanteles manilae (Ashmead, 1904).

Apanteles sydneyensis (Cameron, 1911).

Apanteles narangae (Viereck, 1913).

\section{Diagnosis of Cotesia ruficrus}

(Figs 1 A-C)

Female: Body length $2 \mathrm{~mm}$; general body colour black; legs except hind coxae, tegulae yellowish brown; apices of hind femora and hind tibiae black.

Mesosoma: Mesonotum coarsely and closely punctate posteriorly, scutellum strongly punctate, punctures well separated from each other. Mesopleuron posteriorly and above mostly smooth and shining. Fore wing with first abscissa of radial vein almost equal in length to transverse cubital vein. Hind coxa mostly rugulose. Propodeum coarsely rugose.

Metasoma: Metasoma with first and second tergites rugulose, remaining tergites smooth. Ovipositor sheaths well exserted but not longer than hind tibial spurs.

Host: Larvae of S. frugiperda (Fig. 2).
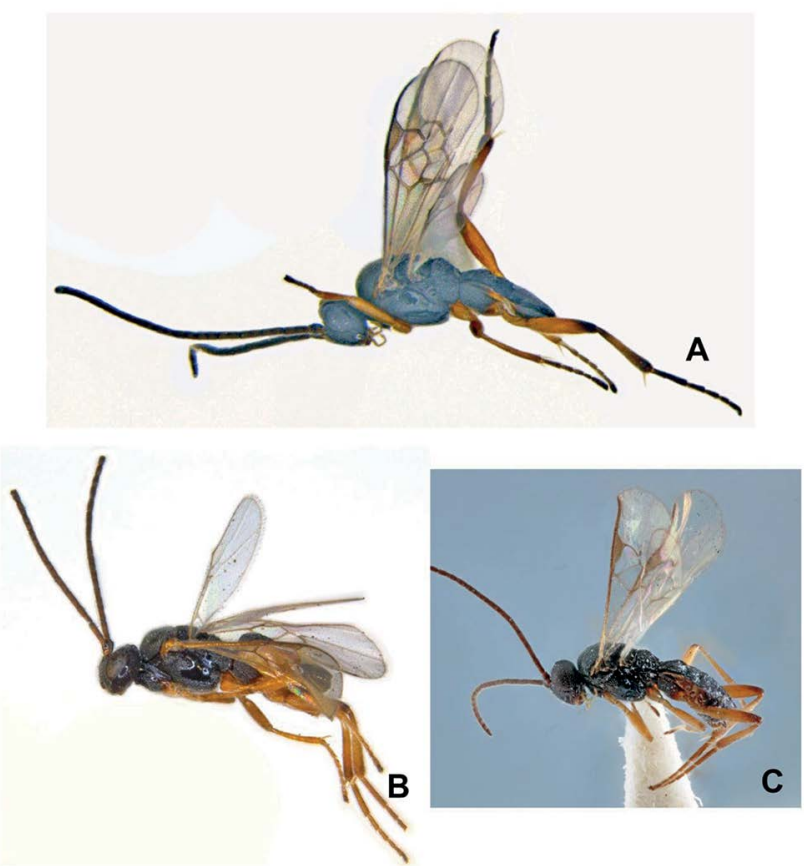

Fig. 1. (A-C) Cotesia ruficrus. A- Karnataka specimen ICAR/ NBAIR/Brac/Microg/Cot/9818, female in habitus; B - Paratype no. 4912, USNM, habitus; C- BMNH specimen, NHMUK010635854 Cotesia ruficrus_nontype_3c 653, habitus.

Cocoons: Gregarious in nature; all the cocoons observed from India were white in colour and arranged in two rows (ranging from 11-29 cocoons per larva) (Fig. 3) contrary to 


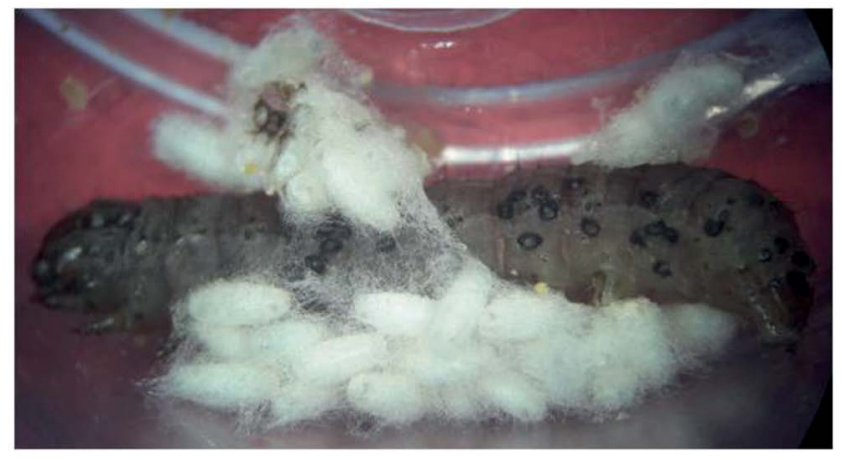

Fig. 2. Spodoptera frugiperda larva with Cotesia ruficrus cocoons in laboratory (Banswara).

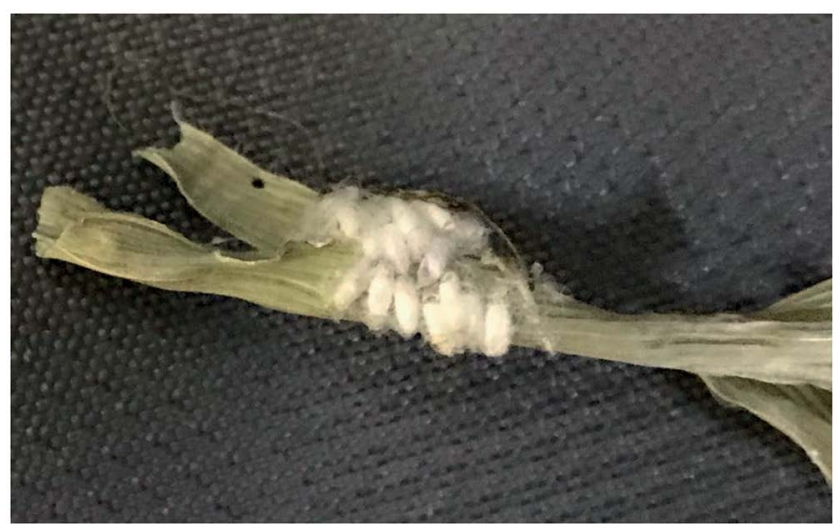

Fig. 3. Cotesia ruficrus cocoons collected from Spodoptera frugiperda larva in maize field (Karnataka).

the yellowish brown cocoons of $A$. narangae mentioned in Wilkinson (1928). However Wilkinson (1928) did mention that cocoons of $A$. sydneyensis were white in colour and cocoons of the Indian specimens were not observed.

Specimens examined: 10 (females and males), INDIA: Karnataka: Bommenahalli, $12.5601^{\circ} \mathrm{N}, 76.3724^{\circ}$ E, 09.viii.2018, ex larva of Spodoptera frugiperda (J. E. Smith), coll. M. Sampath Kumar, specimen code: ICAR/ NBAIR/ $\mathrm{Brac} / \mathrm{Microg} / \mathrm{Cot} / 9818 ; 40$ (females and males), INDIA: Rajasthan: Agricultural Research Station: Borwat Farm: Banswara, located between $73^{\circ} 2^{\prime}$ to $75^{\circ} \mathrm{E}$ ' longitude and $23^{\circ} 11^{\prime}$ to $24^{\circ} 23^{\prime}$ N latitude, $660 \mathrm{mt}$ above msl, 05.vi.2019, coll. S. Ramesh Babu, specimen code: ICAR/ NBAIR/Brac/ Microg/Cot/5719;9 (females and males), INDIA: Andamans: Neil island, ex indet. larva feeding on maize, 27.ii.2012, coll. NBAIR team, specimen code: ICAR/ NBAIR/Brac/Microg/ Cot/27212AN.

Type specimens and vouchers examined at BMNH London: Apanteles antipoda ASHM. paratype; 14; paratype no. 4912; USNM. One female, NHMUK010635854_Cotesia ruficrus_nontype_3c 653 .

Distribution: Afrotropical, Australasian, Neotropical, Oriental, and Palaearctic (Yu et al., 2016). India- present in mainland as well as in Andaman \& Nicobar Islands (Gupta \& Fernández-Triana, 2014).

\section{Molecular characterization of Cotesia ruficrus}

Gupta et al., (2016) have emphasized on the use of integrated approach (combining morphology, host data, and COI gene) as a dependable method of species delimitation for the identification of microgastrine wasps (Braconidae) as they are super diverse and highly speciose. Hence molecular characterization was performed for $C$. ruficrus.

The obtained sequences were aligned using BioEdit sequence alignment editor (version 7.0.5.3) and homology was confirmed using NCBI-BLAST (BLASTn, http:// www. ncbLn1m.nih.gov). The sequences were deposited in the Genbank of National Center for Biotechnology Information (NCBI), USA and accession number obtained (MN337571). The below mentioned submitted sequence shows 95\% query cover with $C$. ruficrus (from Pakistan) with GenBank accession: ARS77476.1 and 96\% query cover with Cotesia sp. SMH-2016 submitted from Meghalaya, India.

Sequence of Cotesia ruficrus (NCBI Accession number - M N337571)

TTAGGAATACCTGGAAGATTAATTGGTAAT GATCAAATTTATAATAGAGTTGTAACTTCTCAT GCATTTATTATAATTTTTTTTATAGTTATACCAG TAATAATTGGTGGATTTGGAAATTGATTAATTC CTTTAATATTAGGTTCTCCAGATATATCTTTCC CTCGAATAAATAATATAAGTTTTTGATTATTAATTC CTTCTTTATTATTATTAATTTTAAGAATATTTAT TAATGTTGGTGTTGGAACAGGATGAACAGTATATC CACCATTATCATTAATTTTAGGTCATGGAGGTA TATCAGTTGATTTAGGAATTTTTTCTTTACATTTG GCTGGTGCTTCATCAATTATAGGAGCTGTTAATTT TATTACTACAATTATTAATATACGTTCTAATTTATT TAATATAGATAAAATATCTTTATTTTCTTGATCAGT GTTTATTACTGCAATTTTATTATTATTATCTTTAC CTGTTTTAGCAGGTGCAATTACTATATTATTAACT GATCGAAATATAAATACTAGATTTTTTGATCCATCAG GTGGTGGTGATCCAATTCTTTATCAACATTTATTTT GATTTTTTGGTCACCTTGGAAGTTT

Shylesha et al. (2018) have documented natural parasitism by egg parasitoids viz., Telenomus sp. (Platygastridae) and Trichogramma sp. (Trichogrammatidae), gregarious larval parasitoid Glyptapanteles creatonoti (Viereck) (Braconidae), solitary larval parasitoid Campoletis chlorideae Uchida (Ichneumonidae), and a solitary 
indeterminate larval-pupal ichneumonid parasitoid. Cotesia ruficrus is a new addition to the existing parasitoid species complex. On an average, $C$. ruficrus emergence ranged from 11-29 wasps/larva. Perhaps with cosmopolitan distribution in addition to being a well established gregarious parasitoid in maize ecosystem, C. ruficrus is emerging as a natural biological control agent of $S$. frugiperda in the maize fields across India. Conservation of this wasp species and relocation of the unhatched wasp cocoons to the infested sites can help in the natural control of the pest.

\section{ACKNOWLEDGMENTS}

Authors are thankful to the Indian Council of Agricultural Research, Dr. C. R. Ballal Director ICAR-NBAIR, Director Research MPUAT, Udaipur and Zonal Director Research ARS, Banswara for research support. Senior author is grateful to Dr Gavin R. Broad (NHM) for hosting her study visit at NHM, London to examine and image the types. The facilities established through RKVY project at Agricultural Research Station, MPUAT, Banswara are also acknowledged.

\section{REFERENCES}

Ashmead WH. 1900. Notes on some New Zealand and Australian parasitic Hymenoptera with description of new genera and new species. Proc Linn Soc NSW 25: 327-360. https://doi.org/10.5962/bhl.part.12157

Ashmead WH. 1904. Descriptions of new genera and species of Hymenoptera from the Philippine Islands. Proc USNM 28(1387): 127-158. https://doi.org/10.5479/ si.00963801.28-1387.127

CABI 2019. Invasive species compendium. https://www. cabi.org/isc/datasheet/29810 (accessed on 21/8/2019).

Cameron P. 1911. On a collection of parasitic Hymenoptera (chiefly bred) made by Mr. W.W.Froggatt, F.L.S., in New South Wales, with descriptions of new genera and species. Part i. Proc Linn Soc NSW 36: 333-346. https://doi.org/10.5962/bhl.part.21902

Folmer O, Black M, Hoeh W, Lutz R, Vrijenhoek R. 1994. DNA primers for amplification of mitochondrial cytochrome c oxidase subunit I from diverse metazoan invertebrates. Mol Mar Biol Biotechnol. 3: 294-299. PMid: 7881515.

Gupta A, Fernández-Triana, JL. 2014. Diversity, host association, and cocoon variability of reared Indian Microgastrinae (Hymenoptera: Braconidae). Zootaxa 3800(1): 001-101. https://doi.org/10.11646/zootaxa.3800.1.1 PMid:24870869

Gupta A, Venkatesan T, More RP. 2016. Morphological and Molecular Characterization of Reared Parasitoid Wasps of the Genus Glyptapanteles Ashmead 1904 (Insecta: Hymenoptera: Braconidae: Microgastrinae) Associated with Lepidoptera in India. Plos One 11(3): e0150765. https://doi.org/10.1371/journal.pone.0150765 PMid:26942740 PMCid:PMC4778878

Haliday AH. 1834. Essay on parasitic Hymenoptera. Entomol Mag. 2(3): 225-259.

Ramasubramanian T, Singaravelu B, Appunu C. 2016. Training Manual on techniques in insect molecular biology and toxicology. ICAR-Sugarcane Breeding Institute, Coimbatore, 100p.

Shylesha AN, Jalali SK, Gupta A, Varshney R, Venkatesan T, Shetty P, Ojha R, Ganiger PC, Navik,O, Subaharan K, Bakthavatsalam N, Ballal CR. 2018. Studies on new invasive pest Spodoptera frugiperda (J. E. Smith) (Lepidoptera: Noctuidae) and its natural enemies. $J$ Biol Control 32(3): 1-7. https://doi.org/10.18311/ jbc/2018/21707

Viereck HL. 1913 Descriptions of ten new genera and twentythree new species of Ichneumonflies. Proc USNM 44: 555-568. https://doi.org/10.5479/si.00963801.1968.555

Wilkinson DS. 1928. A revision of the Indo-Australian species of the genus Apanteles (Hym. Bracon.). Part II. Bull Entomol Res. 19: 109-146. https://doi.org/10.1017/ S0007485300020393

Yu DSK, van Achterberg C, Horstmann K. 2016.Taxapad 2016, Ichneumonoidea 2015. Database on flash-drive. http://www.taxapad.com, Nepean, Ontario. 